\title{
Congenital Adrenal Gland Hypoplasia
}

National Cancer Institute

\section{Source}

National Cancer Institute. Congenital Adrenal Gland Hypoplasia. NCI Thesaurus. Code C35261.

A rare genetic disorder that affects the adrenal gland. It usually presents in infancy with signs and symptoms of adrenal insufficiency. If it is not recognized and treated promptly, it may be lethal. 